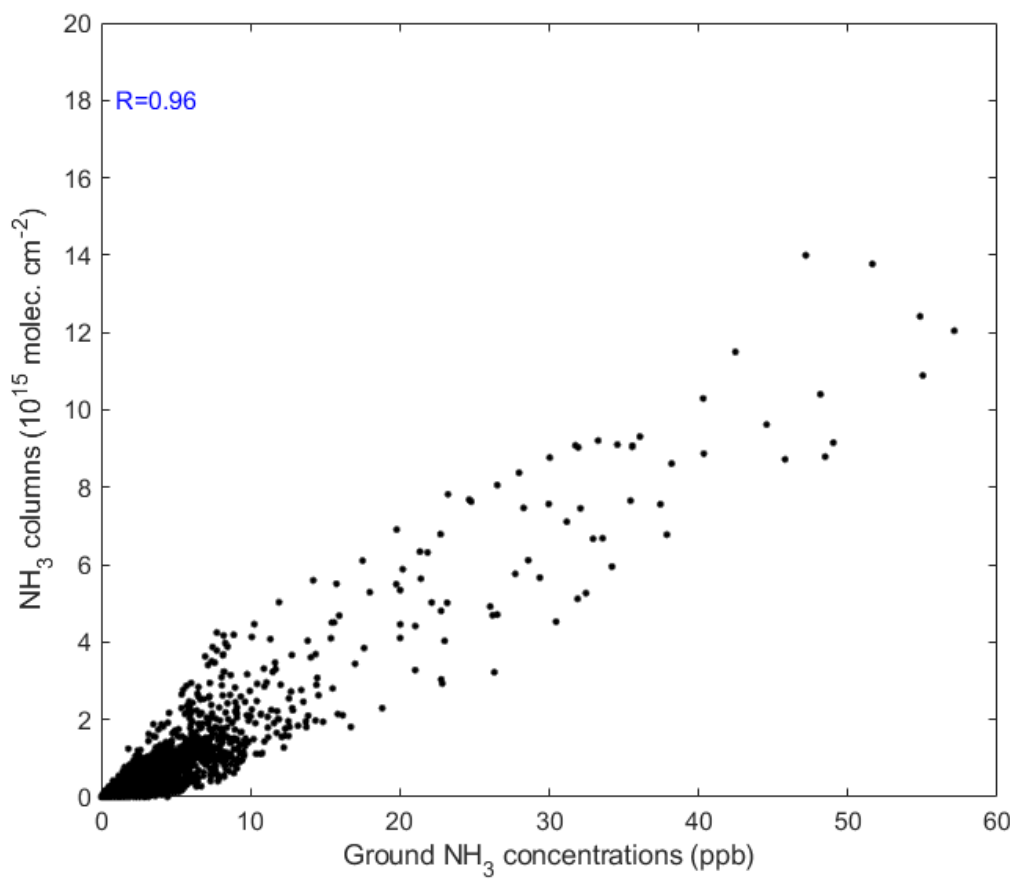

Fig. S1 Correlation of $\mathrm{NH}_{3}$ concentrations at the first layer and $\mathrm{NH}_{3}$ columns from the GEOS-Chem in 2014.

6

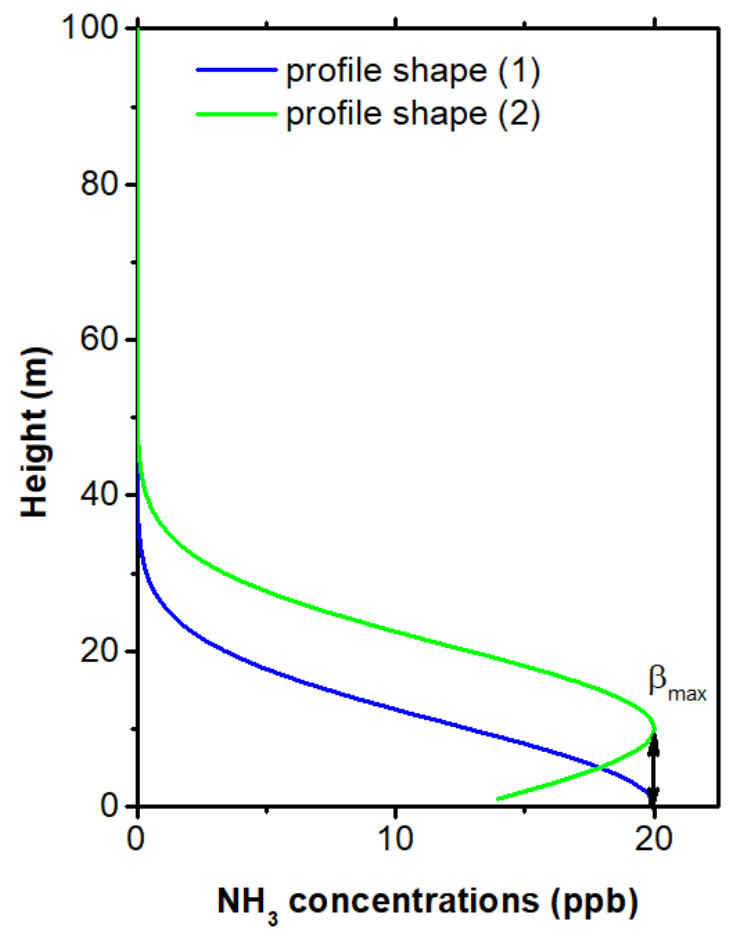

Fig. S2 Two types of shapes of $\mathrm{NH}_{3}$ vertical profiles. 


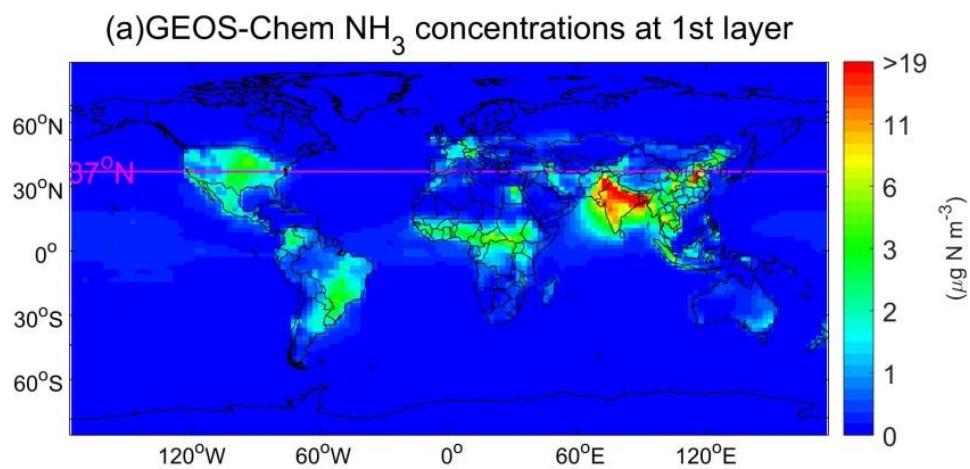

(b)GEOS-Chem $\mathrm{NH}_{3}$ concentrations at 5st layer

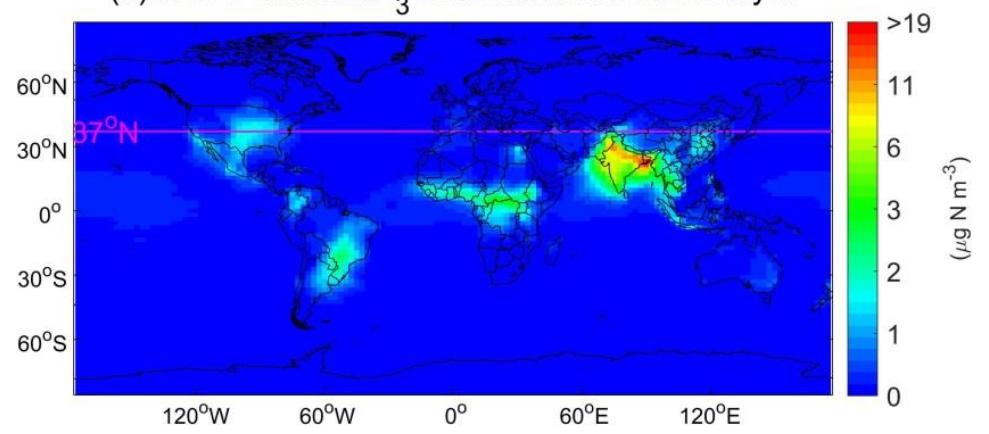

11 Fig. S3 Spatial distributions of $\mathrm{NH}_{3}$ concentrations at first and fifth layers in January, 2014 simulated 12 by GEOS-Chem.

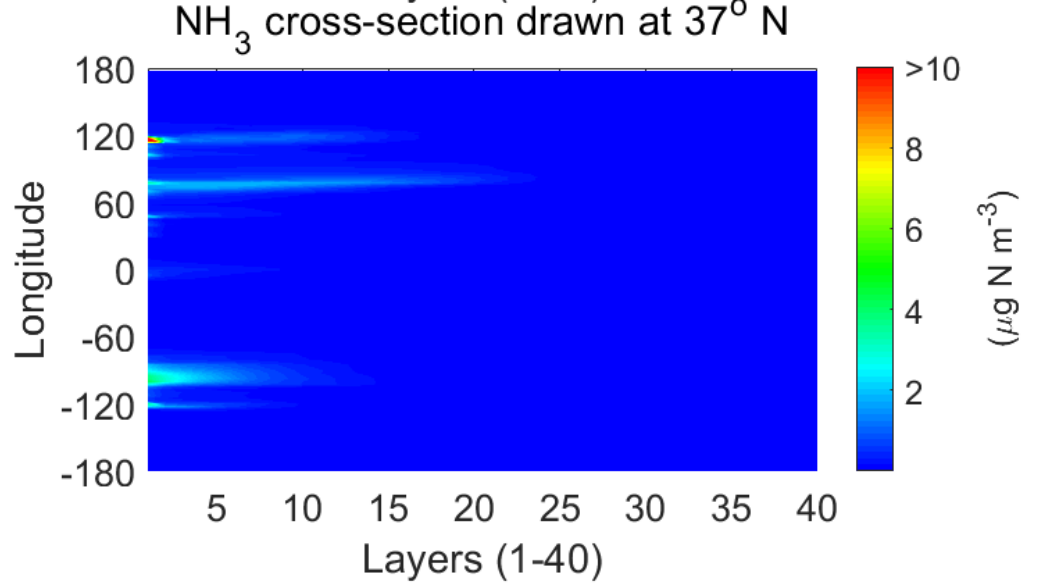

Fig. $\mathrm{S} 4 \mathrm{NH}_{3}$ concentrations with cross-section drawn at $37^{\circ} \mathrm{N}$ in January, 2014 simulated by 18 


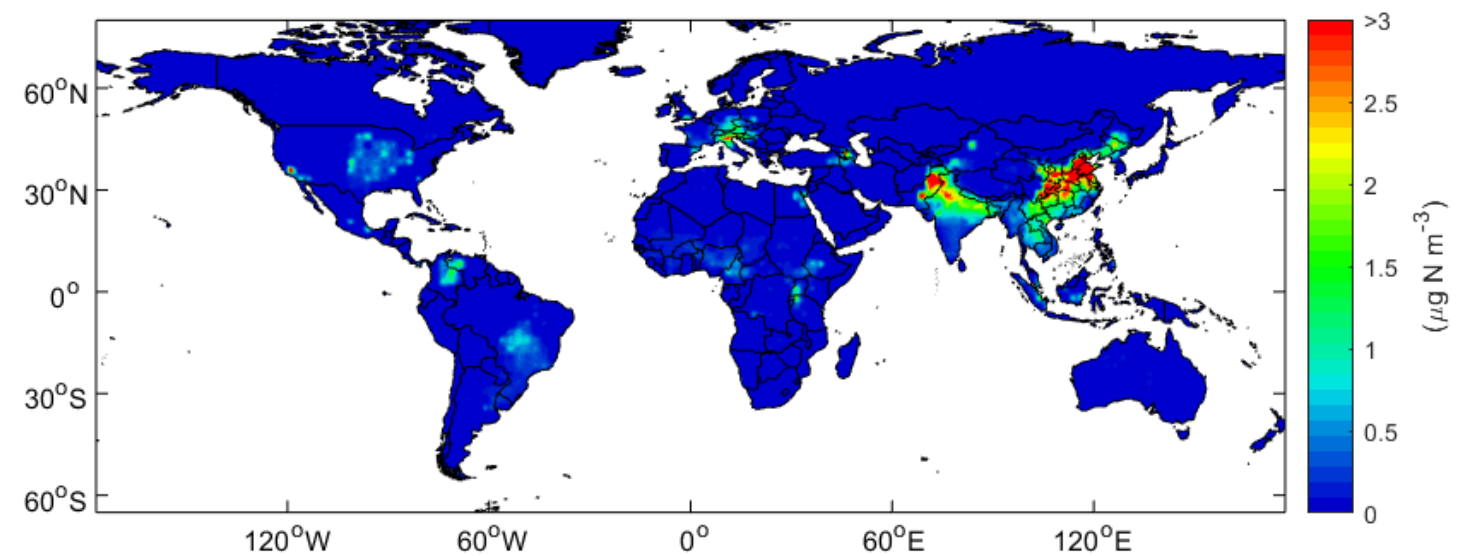

Fig. S5 A case study of sensitivities of $\mathrm{NH}_{3}$ surface concentrations with respect to different heights between $40 \mathrm{~m}$ and $60 \mathrm{~m}$.

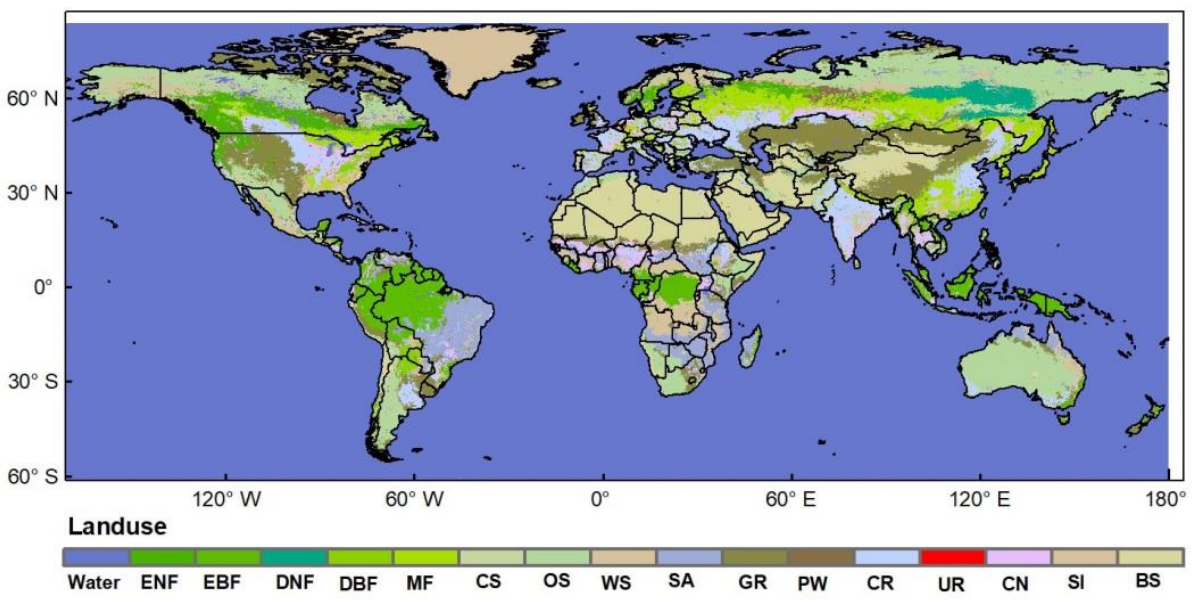

Fig. S6 Land use types. The land use data used in this study are $0.5 \mathrm{~km}$ MODIS-based Global Land Cover Climatology. The successfully full name for each land use type are water, Evergreen Needleleaf Forests, Evergreen Broadleaf Forests, Deciduous Needleleaf Forests, Deciduous Broadleaf Forests, Mixed Forests, Closed Shrublands, Open Shrublands, Woody Savannas, Savannas, Grasslands, Permanent Wetlands, Croplands, Urban and Built-Up, Cropland/Natural Vegetation Mosaic, Permanent Snow and Ice, Barren or Sparsely Vegetated. 


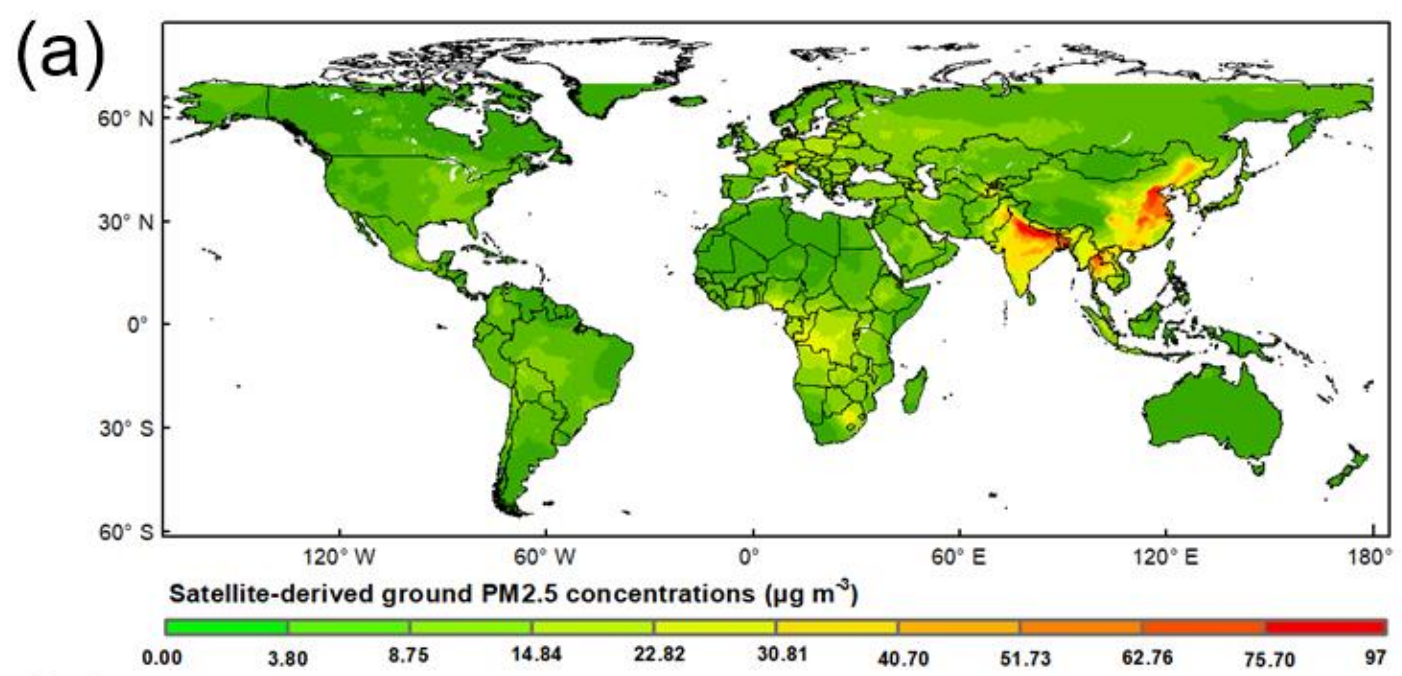

(b)

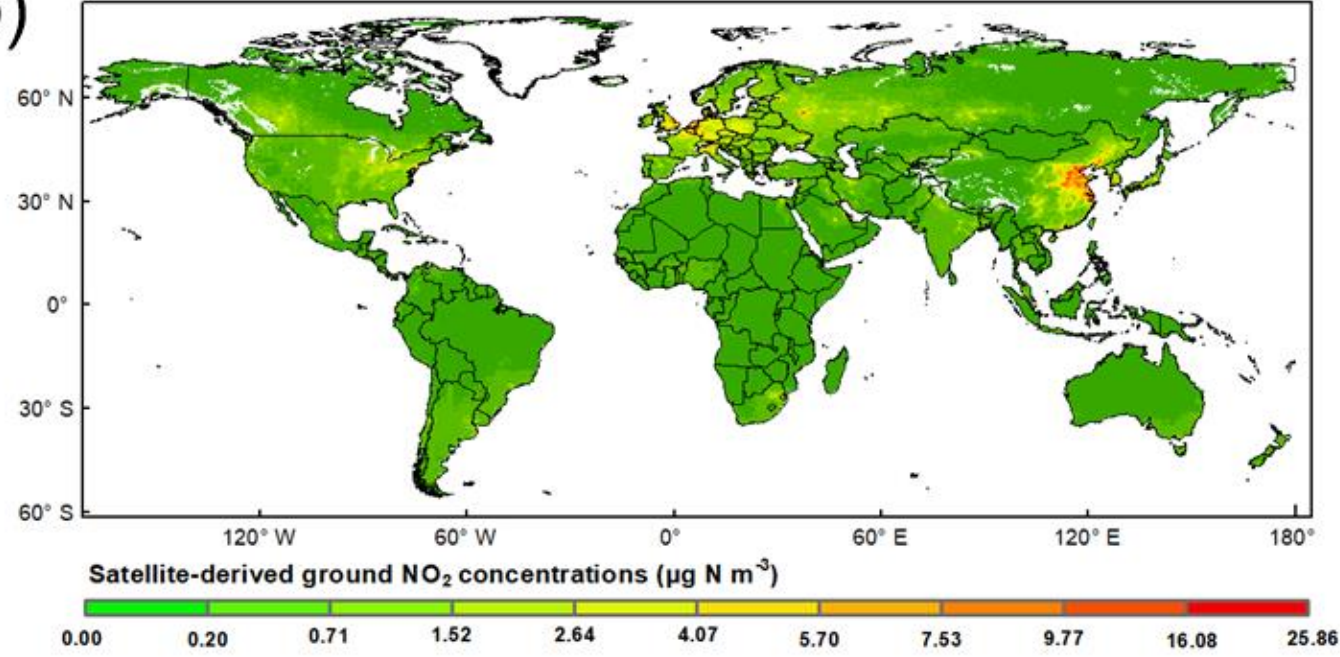

Fig. S7 Spatial distribution of surface $\mathrm{NO}_{2}$ concentration in 2011 (Geddes et al., 2016) and PM2.5 (dust and sea-salt removed) in 2014 (Van et al., 2016).

(a) Fire Counts in January

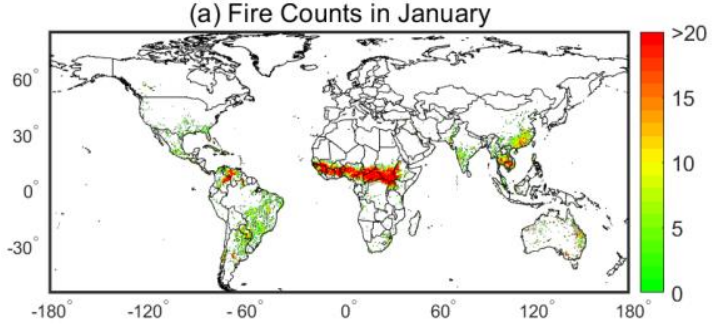

(c) Fire Counts in July

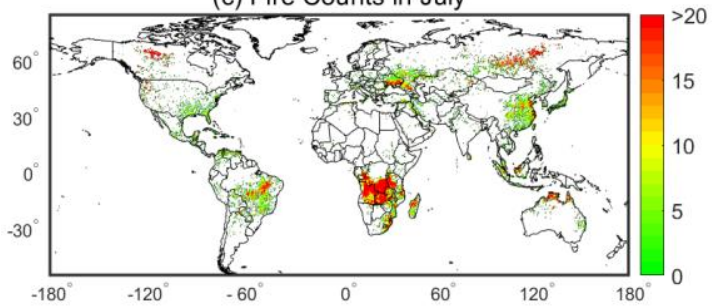

(b) Fire Counts in April

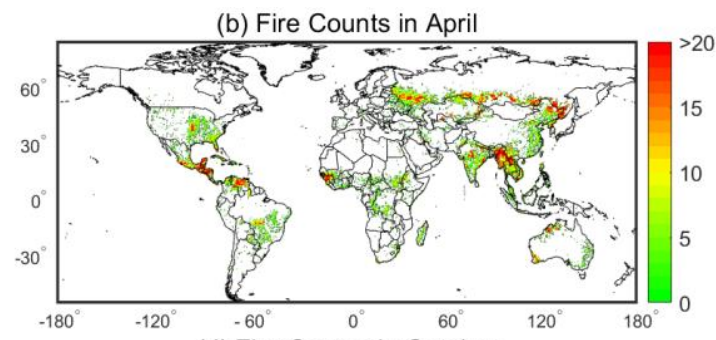

(d) Fire Counts in October

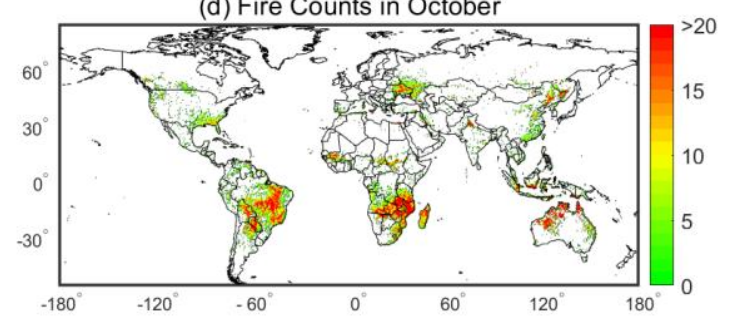

Fig. S8. Global total raw fire counts from the MODIS in January, April, July and October in 2014. 


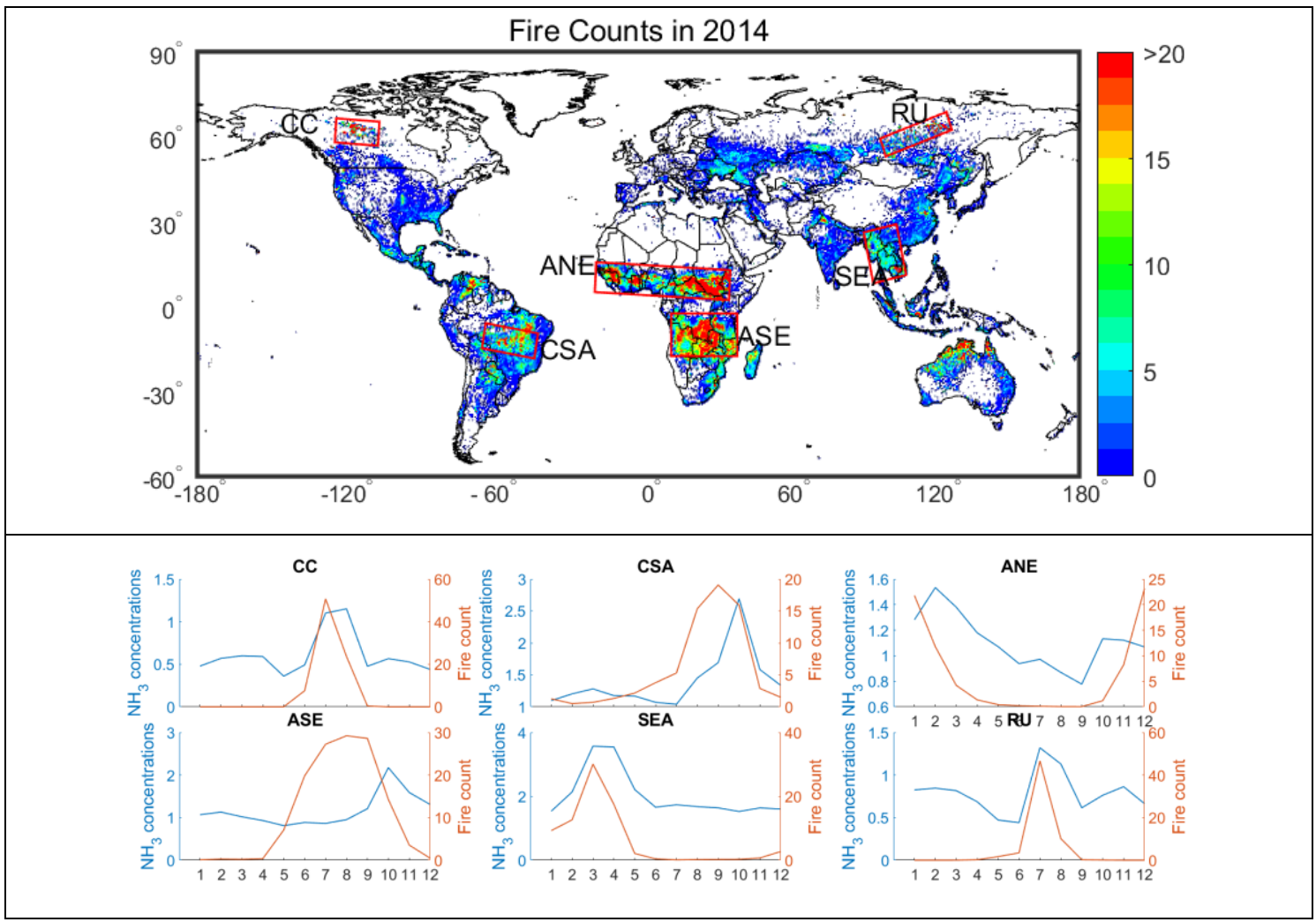

42

Fig. S9 Monthly variations of raw fire counts and ground $\mathrm{NH}_{3}$ concentrations in major biomass burning regions including Central Canada (CC), central South America (CSA), Africa north of Equator (ANE), Africa south of Equator (ASE), South East Asia (SEA) and Central Russia (RU).
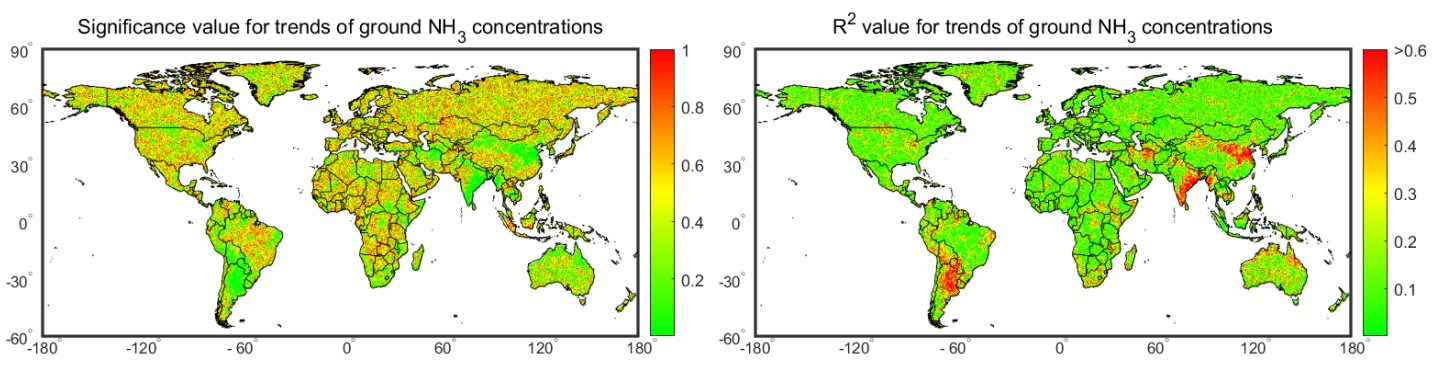

Fig. S10 Significance value (p) and $\mathrm{R}^{2}$ for $\mathrm{NH}_{3}$ trends. 


\section{Land use}

To identify the differences of surface $\mathrm{NH}_{3}$ concentrations in different land use, we used the Global Mosaics of the standard MODIS land cover type data product (MCD12Q1). The MODIS land cover type product (MCD12Q1) is generated based on an ensemble supervised classification algorithm (Friedl et al., 2010). The data set boundaries are $-180.0^{\circ} \sim 180.0^{\circ}$ and $-64.0^{\circ} \sim 84.0^{\circ}$, organized as an array of values uniformly spaced across latitude and longitude with the indexed as $[0,0]$ at $84.0^{\circ}$ latitude, $-180.0^{\circ}$ longitude. Spatially aggregated land use data during 2001-2012 are presented at two spatial resolutions: $5^{\prime} \times 5^{\prime}$ resolution comprising 1776 rows $\times 4320$ columns at a geographic pixel size of approximately $0.083333^{\circ}$; and $0.5^{\circ} \times 0.5^{\circ}$ resolution comprising 296 rows $\times 720$ columns of $0.5^{\circ}$ pixels. The land use data used in this study are $0.083333^{\circ}$ MODIS-based Global Land Cover Climatology. The successfully full name for each land use type are water, Evergreen Needleleaf Forests, Evergreen Broadleaf Forests, Deciduous Needleleaf Forests, Deciduous Broadleaf Forests, Mixed Forests, Closed Shrublands, Open Shrublands, Woody Savannas, Savannas, Grasslands, Permanent Wetlands, Croplands, Urban and Built-Up, Cropland/Natural Vegetation Mosaic, Permanent Snow and Ice, Barren or Sparsely Vegetated.

\section{Surface $\mathrm{NH}_{3}$ concentrations in different land use types}

In terms of different land use types, the surface $\mathrm{NH}_{3}$ concentrations in China were highest in the cropland $\left(4.6 \mu \mathrm{g} \mathrm{N} \mathrm{m}^{-3}\right)$, followed by urban land $\left(3.9 \mu \mathrm{g} \mathrm{N} \mathrm{m}^{-3}\right)$, forest land $\left(2.7 \mu \mathrm{g} \mathrm{N} \mathrm{m}^{-3}\right)$, grass land $\left(1.8 \mu \mathrm{g} \mathrm{N} \mathrm{m}^{-3}\right)$ and water $\left(1.9 \mu \mathrm{g} \mathrm{N} \mathrm{m}^{-3}\right)$ (Table S1); in the US, the surface $\mathrm{NH}_{3}$ concentrations in the cropland were $2.5 \mu \mathrm{g} \mathrm{N} \mathrm{m}{ }^{-3} \mathrm{y}^{-1}$, which were obviously higher than the values of $1.8,1.4,1.7$ and $1.1 \mu \mathrm{g} \mathrm{N} \mathrm{m}^{-3}$ in urban, forest, grass and water lands, respectively; in Europe, the surface $\mathrm{NH}_{3}$ concentrations in the urban land $\left(2.3 \mu \mathrm{g} \mathrm{N} \mathrm{m}^{-3} \mathrm{y}^{-1}\right)$ were similar to the value in the cropland ( $2.6 \mu \mathrm{g} \mathrm{N}$ $\left.\mathrm{m}^{-3} \mathrm{y}^{-1}\right)$. 

97

98

\begin{tabular}{lllllll}
\hline & Crop & Urban & Forest & Grass & Water & Mean \\
\hline China & 4.60 & 3.93 & 2.67 & 1.78 & 1.93 & $2.38(0.22-15.11)$ \\
US & 2.51 & 1.78 & 1.44 & 1.67 & 1.07 & $1.52(0.14-10.59)$ \\
Europe & 2.29 & 2.59 & 1.90 & 1.34 & 1.07 & $1.79(0.04-9.49)$ \\
\hline
\end{tabular}

In China, US and Europe, high surface $\mathrm{NH}_{3}$ concentrations in the cropland area were reasonable because the agriculture is the major source of the global $\mathrm{NH}_{3}$ emissions with $\mathrm{N}$ fertilizations, and high $\mathrm{NH}_{3}$ emissions in the cropland lead to high surface $\mathrm{NH}_{3}$ concentrations. However, high surface $\mathrm{NH}_{3}$ concentrations were also observed in the urban area in China, US and Europe. This result is mainly due to that the vehicles can emit considerable $\mathrm{NH}_{3}$ since there are no vehicle emission standards to regulate $\mathrm{NH}_{3}$ to date. Our results confirm that the urban is also a major source of $\mathrm{NH}_{3}$ in the city around the globe, which is consistent with the measurements by a previous study (Sun et al., 2017) using the mobile laboratory observations to characterize $\mathrm{NH}_{3}$ in the US and China. On the other hand, the high surface $\mathrm{NH}_{3}$ concentrations in urban area can also related with long distance transmission from the suburban areas (intensive livestock production or $\mathrm{N}$ fertilizer application) due to the rapid urbanization shortening the distance between suburban and urban regions (Gu et al., 2014). 


\section{Reference}

Friedl, M. A., Sulla-Menashe, D., Tan, B., Schneider, A., Ramankutty, N., Sibley, A., and Huang, X.: MODIS Collection 5 global land cover: Algorithm refinements and characterization of new datasets, Remote Sensing of Environment, 114, 168-182, https://doi.org/10.1016/j.rse.2009.08.016, 2010.

Geddes, J. A., Martin, R. V., Boys, B. L., and van Donkelaar, A.: Long-term trends worldwide in ambient $\mathrm{NO}_{2}$ concentrations inferred from satellite observations, Environmental Health Perspectives (Online), 124, 281, 2016.

Gu, B., Sutton, M. A., Chang, S. X., Ge, Y., and Chang, J.: Agricultural ammonia emissions contribute to China's urban air pollution, Frontiers in Ecology and the Environment, 12, 265-266, 2014.

Sun, K., Tao, L., Miller, D. J., Pan, D., Golston, L. M., Zondlo, M. A., Griffin, R. J., Wallace, H. W., Leong, Y. J., Yang, M. M., Zhang, Y., Mauzerall, D. L., and Zhu, T.: Vehicle Emissions as an Important Urban Ammonia Source in the United States and China, Environmental Science \& Technology, 51, 2472-2481, 10.1021/acs.est.6b02805, 2017.

Van, D. A., Martin, R. V., Brauer, M., Hsu, N. C., Kahn, R. A., Levy, R. C., Lyapustin, A., Sayer, A. M., and Winker, D. M.: Global Estimates of Fine Particulate Matter using a Combined Geophysical-Statistical Method with Information from Satellites, Models, and Monitors, Environmental Science \& Technology, 50, 3762, 2016. 